\title{
Virtual Prototype and 3D Printing of Bud Chipping Machine for Agriculture
}

\author{
Rajkumar.E, Manojkumar.E
}

\begin{abstract}
Sugarcane is a primary crop in many parts of India. The seed or bud of the sugarcane is a part of the plant itself. Due to complicated and expensive tools, separating bud from the plant is a difficult process. Use of plant for its raw materials and products leads to loss of buds whereas planting buds with the plant leads to loss of plant products. Current machines used for sugarcane bud cutting require skill and training but are also unsafe. The risk of injury is also high. Thus, there is a need for the development of the bud chipping machine which satisfies the above criterion. The research was done by conducting a literature survey, patent search, and market survey. Designing and modeling of machine is carried out by considering aspects of design and human ergonomics. Hence, the simple and effective machine is designed which can be used to cut sugarcane buds without much effort, reduced loss of plant product, reduced muscular problems and can be safely operated.
\end{abstract}

Keywords: Bud chipping, agriculture equipment, cutting blade.

\section{INTRODUCTION}

I India is currently the second largest producer of sugar in the world according to statistics collected for the period 2017-2018 contributing nearly $14 \%$ to the world sugar production. It is estimated that the sugarcane industry provides employment for more than 6 million people in India. Thus, many farmers in India grow sugarcane as a primary crop and this crop becomes their primary source of income. The buds of the sugarcane shown in Figure.1 grow within itself and removing them is difficult due to various complexities involved. The remaining part of the sugarcane can be used to make products related to sugar such as jaggery, fibre, chemicals, etc. However due to the aforementioned difficulties, the entire stem has to be planted to regrow sugarcane or the bud must be wasted in order to obtain the products. Removing the bud manually involves beating of sprout physically and is thus a time consuming and a very labour intensive process. It can also lead to various muscular problems. Thus farmers have to choose between either planting the crop to regrow it or using the sugarcane to create products or painstakingly separate buds from sugarcane to obtain both. Farmers separate their crop to plant them again and the rest to obtain raw materials and products. They usually do not remove buds. This leads to a loss of crop production as less buds are available to regrow crops and also loss of revenue as they are not able to sell the entire sugarcane for making products.

Revised Manuscript Received on October 31, 2019.

* Correspondence Author

Dr.Rajkumar.E*, Department of design and Automation School of Mechanical Engineering, VIT, Vellore, Tamil Nadu, India. Email: rajkumar.e@vit.ac.in

Manojkumar.E, Department of design and Automation School of Mechanical Engineering, VIT, Vellore, Tamil Nadu, India.

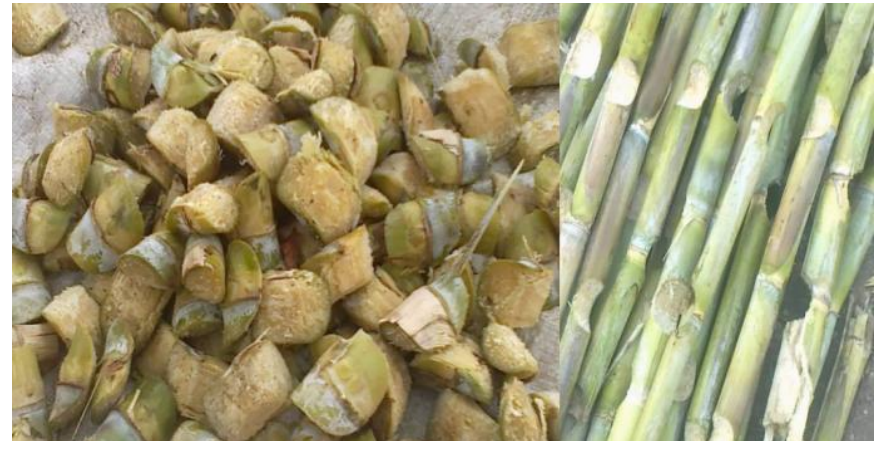

Figure.1 Buds of a Sugarcane

A sugarcane bud chipping machine which is simple, effective, safe and cheap was thus necessary. Research was carried out to obtain the characteristics required. A foot pedal operated machine is designed with simplicity and ease of use in mind. The machine can easily separate buds from the sugarcane without much skill and labour and in short period of time. This machine also reduces manpower used in this process because this machine operated by a single person only. Whitworth quick return mechanism is utilized to reduce idle time. 3D printing is a relatively new way of manufacturing components in which they are additively built in layers from CAD data. This is different from traditional machining processes which involve removal of material from stock to obtain components. 3D printing has reduced lead time, cost and enhanced design freedom. By 3D printing we can produce the prototype of components and get an idea about how the components look like physically. The components can also be analysed for further improvement in design. 3D printing is very useful in case of prototype making, pattern making, and inspection of design for actual part.

\section{LITERATURE REVIEW}

Ningappa H. Kuri[1] has designed a hand operated torque based machine for cutting buds. The machine is simple and effective, however is unsafe and non-ergonomical. It can only separate buds from small pieces of sugarcane. Sanjay Patil et.al [2] designed a motor operated bud chipper. This is efficient and ergonomical but is costly for rural people to buy. It consumes electicity also. It also operates continuously so chances of injury is more than that of manually operated sugarcane bud chipping machine. Rushikesh S. Patel et.al [3] developed a cam operated sugarcane bud cutting machine. A cam operated by motor is used to guide the cutting blade connected by shaft and gear train to control speed. The machine developed has a lot of moving components making it bulky and subject to wear and tear. Rahul A. Sonawane et.al [4] also designed a motor operated bud chipper. 


\section{Virtual Prototype and 3D Printing of Bud Chipping Machine for Agriculture}

The machine has high efficiency, reduced lead time and less skill requirement. However, this requires a large amount of electricity to run on. Electricity may not be available in all parts of India thus making the machine not usable at all times.RoshanlalVishvakarma[9], a farmer in Madhya Pradesh noticed the difficulty in separating buds from the sugarcane and designed a hand operated bud chipper. It utilizes a simple linkage mechanism. But it is not ergonomically designed and hence longer duration of use of machine can cause muscular problems.

\section{METHODOLOGY}

A sugarcane bud chipping machine which is cost feasible, easy to operate and ergonomic was to be designed. Extensive literature review and patent search was done in this area to determine the faults and scope of improvement of the existing machines to design the machine with the stated conditions. A suitable design was conceptualized and drafted using SolidWorks software. The components were fabricated and simulated using 3D printing technology with Repetier software to obtain necessary data for analysis. This was used to optimize the components and produce the final assembly. The entire process is represented by the flowchart in Figure.2.

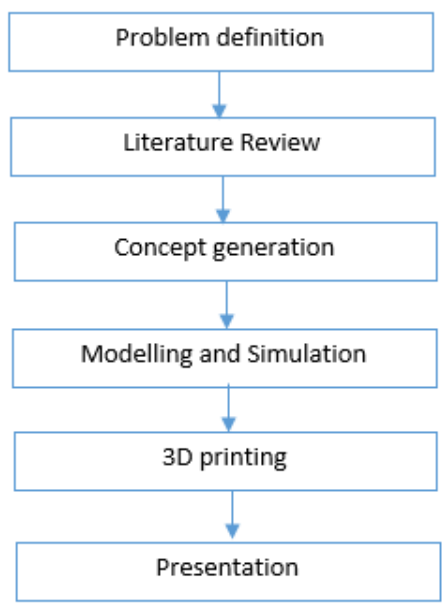

Figure 2. Methodology

\section{A. Solid modelling:}

Assembly of bud chipping machine is shown in Figure.3.

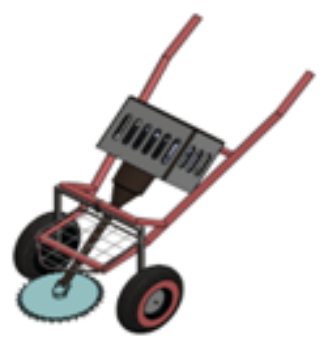

Figure. 3. bud chipping machine assembly

\section{C.Bud chipping machine components:}

The components in sugarcane bud chipping machine are shown in Figure.4.

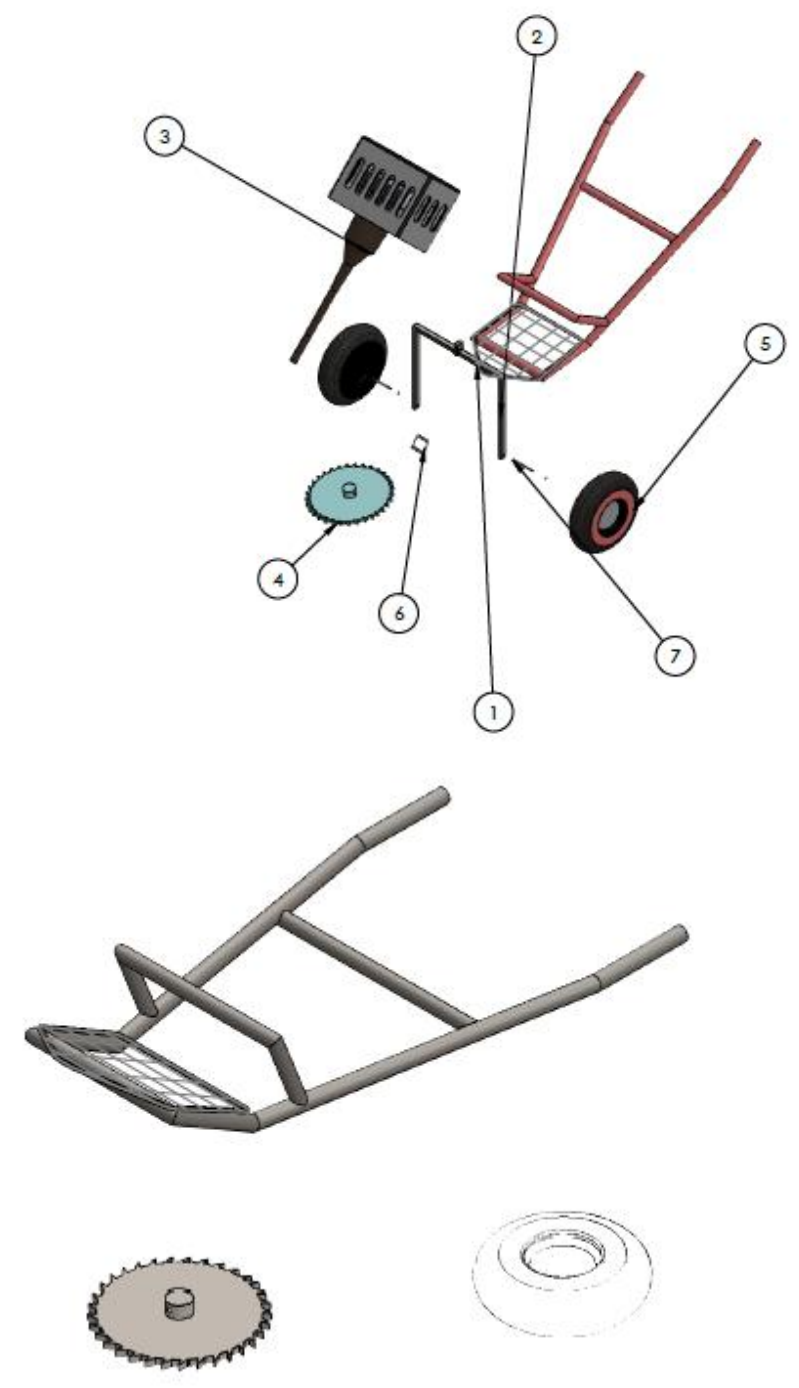

Figure.4. Components of bud chipping machine

D. Orthographic view of bud chipping machine: Orthographic views of bud chipping machine assembly is shown in figure 5 .
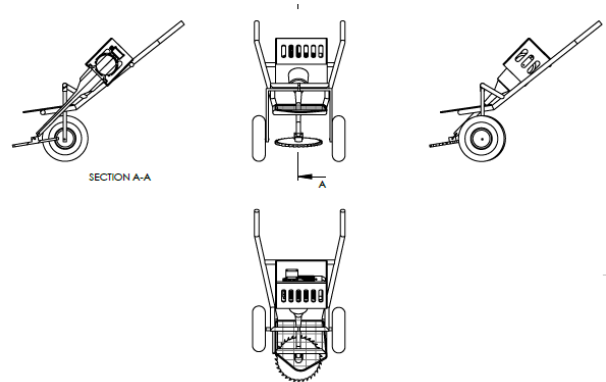

Figure.5 Different views of bud chipping machine assembly

\section{E. Design Criteria and assembly components}

Bud chipping assembly is designed by considering weight of the components which is directly affects the power consumption. We know that as power increases and /or performance decreases. This is take it into account for design of housing. 
$\Delta \mathrm{W}$ due to weight $=22 \% \mathrm{X}$ total weight increment

$\Delta \mathrm{W}$ due to power increase $=4.5 \% \mathrm{x}$ total weight $\mathrm{x}$ power increment

\section{F. Design Procedure:}

Step 1: Design of Stand provides the stability to the whole machine and it bears all the weight of it. Proper stand design is necessary in order for good transmission of operating vibrations.The stand wire frame is drawn first later the weldments are given as the cross section which forms the entire stand.

Step 2: Design of Housing consists of rectangular shell used to cover the gears and the feed rollers. It is also used to restrict the movement of grass outside the cutting zone.

Step 3: Gear assembly consists of three bevel gears out of which two are of same dimensions whereas the other is of higher diameter in order to reduce the speed of the feed rollers.Gears are imported from the parametricgeometry available in the solid works and then assembled according to the required condition.

Step 4: Design of blade such a way that should be detachable as they may go blunt on long usage.

\section{G. 3D printing: CURA software Simulation}

Using cura software model scaling was done. In order to reduce time of printing, scale was reduced to $30 \%$ of the original dimensions. Also coordinates were set in order to avoid errors. Fine quality printing was selected and was checked in layer view mode of cura before printing for ensuring whether parts will be printed properly or not. After this G-code file was generated and this file was given as input to a $3 \mathrm{D}$ printer for carrying out the operation. In this software we can load our ".stl" file or ".amf" file of our model. Then we can rotate and scale our model as per requirement and then slicing can be done as per required parameters like infill pattern (honeycomb rectilinear, concentric and etc.), solid infill pattern (rectilinear and concentric) and infill density in percentage. After this process we can slice with the option given in the right side dialogue box and we can see estimated 3D printing time for model and we can generate $\mathrm{G}$ code by saving that file. This $\mathrm{G}$ code file can directly run on $3 \mathrm{D}$ printer by using USB or memory card. Bud Chipping assembly is imported to CURA to check the tool path and the time taken to manufacture the parts of the assembly. For the scaled assembly the time taken to print is around $2 \mathrm{hrs}$.

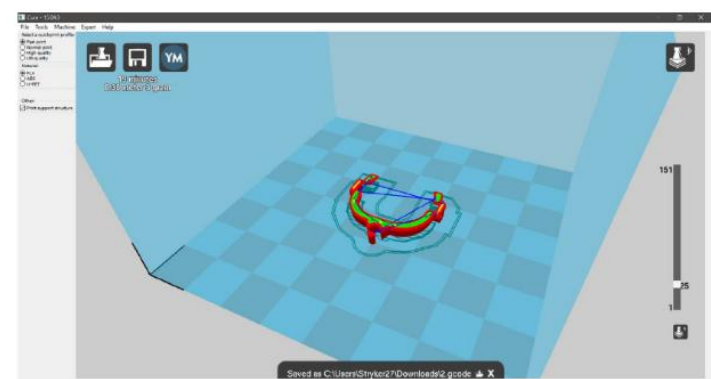

Figure. 6.3D printing simulation of bud chipping assembly component

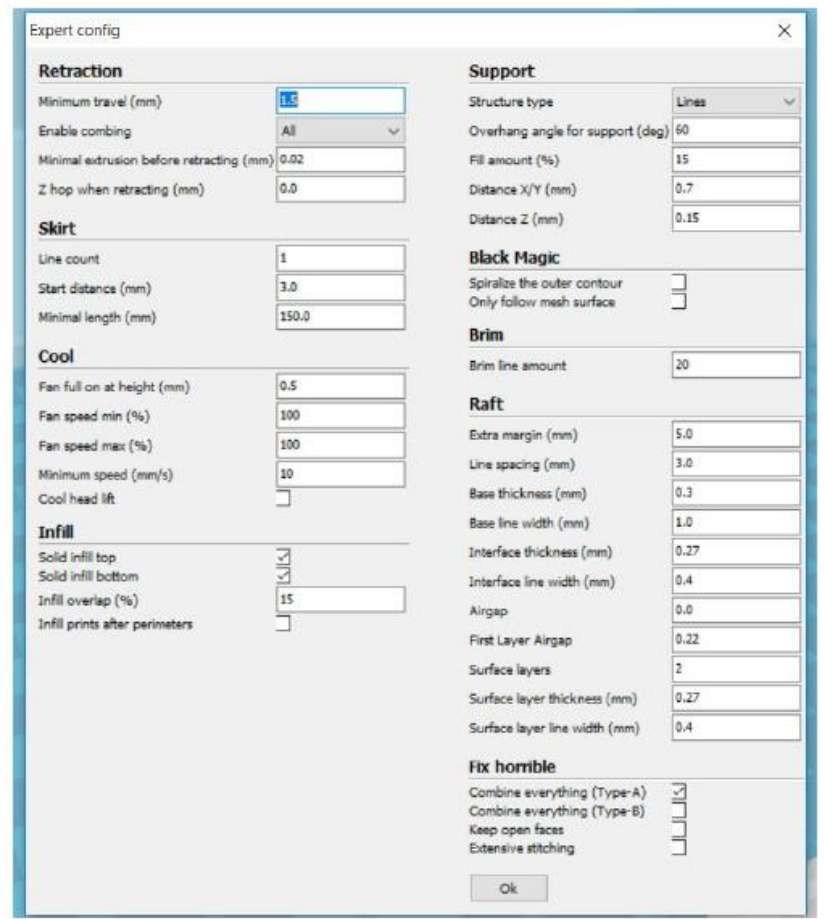

Figure.7 3D printing conditions using Cura

\section{H. 3D printing procedure of components in 3D Printer}

As stated above, the part's $G$ code file was generated by using Cura software and then it was taken into memory card and was inserted into 3D printer. First, we have to stick tap on the bed surface and apply some glue on that surface (so that part remains firmly at surface). Then we have to set bed temperature up to $46-48 \mathrm{deg}$. and nozzle temperature up to 235-240 deg. Then select "print from SD card" and select G code file of model. After selecting that option, the 3D printing of model starts and on screen we can see nozzle, bed temperature, percentage of completion of model and time. Hence by 3D printing of parts we can produce the prototype of parts and we get an idea about how our parts will look physically and where can we change our design or make any improvement in the design. 3D printing is very useful in case of prototype making, pattern making, and inspection of design for actual part.

\section{CONCLUSION}

This design provides more options for farmers and implementing this on the hybrid of electric motor machine should give high flexibility for the operators.

The inclusion of handle bar at the back of the machine gives good ergonomic advantage. More innovation should be encouraged in the dairy industry as it is ever lasting and never goes out of market. $3 \mathrm{~d}$ printing simulation gives real time manufacturing simulation. Animations and manipulability of machine elements using established chaff cutting designs allow the user to better understand the virtual design. We believe that such a system will be useful to operators, engineers and managers. 


\section{REFERENCES}

1. Ningappa H. Kuri, "Design and development of sugarcane bud cutting machine", International Journal of Research in Aeronautical and Mech. Engineering,Vol 5, Issue 2.pg. 97-110.

2. Sanjay Patil, Nikhil Nangare, AdityaWaghmare, MayurZope, Meet Thakker, "Design and modification of bud scooping machine", International Research Journal of Engineering and Technology, Vol 3, Issue 4, pg 2743-2747.

3. Rushikesh S. Patil, Dnyaneshwar B. Patil, Dushyant M. Patil, Shashikant B. Khandagale, "Cam Operated Sugarcane Bud Cutting Machine", International Research Journal of Engineering and Technology, Vol 5, Issue 10, pg 140-147.

4. Rahul A. Sonawane, Jagdish R. Waybhase, Rushikesh B. Yengupatla, Shumail S. Shaikh, Praveen K. Mali, "Design and development of sugarcane sprout cutter machine by human powered flywheel motor concept", International Journal of Emerging Trends and Technology in Computer Science, Vol 6, Issue 3, pg 34-44.

5. Anand Kumar Telang, Design and Modal Formulation of Power Operated Chaff Cutter, International Journal on Emerging Technologies (Special Issue on ICRIET-2016) 7(2): 181-187(2016).

6. Kalaiselvan P, Kesavan P, Satheeshkumar p, Karthikeyan m Sakthivel, Baluvenkatesh, Fabrication And Performance Measurement Of Manually Powered Fodder Cutter, International Journal of Scientific \& Engineering Research, Volume 7, Issue 5,May-2016.

7. ChinmayBandiwadekar, AjinkyaKamble, VivekGarala, ZuberShaikh. Review Paper on Design \& Development of Chaff Cutting Machine. IJSRD - International Journal for Scientific Research \& Development| Vol. 4, Issue 02, 2016 | ISSN (online):2321-0613.

8. VishrutRaut, Prof.S.M.Fulmali, Design \&Modelling of Mobile Chaff Cutter a Review, International Conference on Ideas, Impact and Innovation in Mechanical Engineering (ICIIIME2017).

9. RoshanlalVishwakarma, "Sugarcane bud chipper", Fifth National Grassroots Innovation, Patent No. 1501/MUM/2008. 